\title{
Taste and Odour Disturbances in Pediatric Patients Undergoing IV Flush with Normal Saline Administered by Prefilled or Freshly Prepared Syringes: Randomized Single-Blind Study
}

\author{
David Mancini, Régis Vaillancourt, Annie Pouliot, Alice Lin, and Diane Sharp
}

\begin{abstract}
Background: Previous studies have reported the occurrence of taste and odour disturbances among patients undergoing IV flush with prefilled syringes of $0.9 \%$ sodium chloride (normal saline [NS]). These disturbances have been attributed to the leaching of volatile substances into the NS from the plastic of the syringe. To date, there have been no studies comparing the occurrence of taste and odour disturbances with different NS preparations.

Objective: To compare the occurrence of taste and odour disturbances in pediatric patients undergoing IV flush with commercially available prefilled NS syringes and NS syringes prepared fresh daily.

Methods: Patients aged 6 to 18 years who underwent routine flushing of central or peripheral IV tubing were asked to participate in this followup randomized single-blind study. Flushing was performed with NS from BD PosiFlush $10-\mathrm{mL}$ sterile prefilled syringes or NS transferred from a polyolefin bag (Baxter AVIVA) to a polypropylene syringe and stored for a maximum of $12 \mathrm{~h}$ before use.
\end{abstract}

Results: Fifty pediatric patients (mean age \pm standard deviation $13.4 \pm$ 3.8 years) who had undergone flushing of IV tubing with NS were interviewed. Taste or odour disturbances were reported by 18 (72\%) of the 25 patients who underwent flushing with NS from a prefilled syringe, whereas only 1 (4\%) of the 25 who underwent flushing with NS from a freshly prepared syringe experienced such disturbances $(p<0.001)$.

Conclusions: There were significant differences in taste and odour disturbances experienced by patients who underwent IV flush with commercial prefilled NS syringes and freshly prepared NS syringes.

Keywords: taste disturbance, odour disturbance, prefilled syringes, saline IV flush, fresh syringe

\section{RÉSUMÉ}

Contexte : Des études antérieures ont signalé des cas d'altération du goût et de l'odorat chez des patients lors du rinçage de leur tubulure intraveineuse (i.v.) au moyen de seringues préremplies d'une solution de chlorure de sodium à $0,9 \%$ (solution physiologique salée [SP]). Ces cas d'altération ont été attribués à des substances volatiles qui se seraient échappées du matériel composant la seringue plastique pour passer dans la SP. À ce jour, aucune étude comparant les cas d'altération du goût et de l'odorat en fonction de l'utilisation de différentes SP n'a été effectuée.

Objectif : Comparer les cas d'altération du goût et de l'odorat chez des enfants dont la tubulure i.v. a été rincée à l'aide d'une seringue commerciale préremplie de SP et chez ceux pour qui on a utilisé une seringue de SP préparée le jour même.

Méthodes : On a demandé à des patients âgés de 6 à 18 ans chez qui on procédait à un rinçage habituel de leur tubulure i.v. périphérique ou centrale de participer à cette étude complémentaire avec répartition aléatoire et à simple insu. Le rinçage a été effectué à l'aide de la SP de seringues stériles préremplies BD PosiFlush de $10 \mathrm{~mL}$ ou à l'aide de SP prélevée d'un sac de polyoléfine (Baxter AVIVA) et introduite dans des seringues de polypropylène conservées pendant une période ne dépassant pas 24 heures avant l'utilisation.

Résultats : Cinquante enfants (l'âge moyen \pm l'écart-type était de 13,4 \pm 3,8 ans) chez qui on a procédé à un rinçage de leur tubulure i.v. à l'aide d'une SP ont été interviewés. Des cas d'altération du goût ou de l'odorat ont été signalés par 18 (72\%) des 25 patients chez qui on a procédé à un rinçage à l'aide de la SP d'une seringue préremplie, alors qu'un seul (4\%) des 25 patients chez qui on a procédé à un rinçage à l'aide de la SP d'une seringue remplie dans les 24 heures précédentes a signalé un cas d'altération $(p<0.001)$.

Conclusions : On a constaté d'importantes différences en ce qui a trait aux cas d'altération du goût et de l'odorat entre les patients chez qui on a procédé au rinçage des tubulures i.v. à l'aide de seringues commerciales préremplies de SP et ceux chez qui ont été utilisées des seringues remplies de SP dans les 24 heures précédentes.

Mots clés : altération du goût, altération de l'odorat, seringues préremplies, solution salée i.v. pour le rinçage, seringue préparée le jour même

[Traduction par l'éditeur] 


\section{INTRODUCTION}

prior observational study conducted at the Children's $\mathrm{A}_{\text {Hospital of Eastern Ontario, in Ottawa, Ontario, measured }}$ the incidence of odour and taste disturbances among pediatric patients undergoing flushing of IV tubing with $0.9 \%$ sodium chloride (normal saline [NS]) from commercially available prefilled syringes. In that study, $73 \%$ of the patients experienced a disturbance of taste or odour. ${ }^{1}$ Such disturbances have been attributed to the leaching of nontoxic, volatile substances from the polypropylene resin of the syringe into the NS. After injection of the solution, these substances are expelled from the body during expiration, which results in unpleasant taste and odour sensations. ${ }^{1,2}$ Taste and odour are important clinical considerations for patients who are receiving medications that are likely to induce nausea. ${ }^{3,4}$

The current study compared the occurrence of taste and odour disturbances in pediatric patients undergoing IV flush with NS from commercially available prefilled syringes and with freshly prepared NS. The participants in the study were blinded to the IV flush solution, which strengthened the analysis.

It was hypothesized that patients undergoing IV flush with fresh NS would have fewer taste and odour disturbances than those undergoing IV flush with NS from prefilled syringes.

\section{METHODS}

The CHEO Research Ethics Board approved this 2-arm, randomized, single-blind study. The study was conducted from January 30, 2013, to June 13, 2014, exclusively at the Children's Hospital of Eastern Ontario, a tertiary care teaching facility in Ottawa, Ontario.

\section{Inclusion and Exclusion Criteria}

The study included inpatients 6 to 18 years of age who were undergoing routine flushing of central or peripheral IV tubing with NS.

Patients with the following characteristics were excluded: known developmental delays, as stated in the patient's chart; Bell palsy, as stated in the patient's chart; previous participation in the study; discomfort with the task, according to the nurse's clinical judgment; documented recent abdominal pain, head trauma, rhinorrhea, oral infection, or cough; eating or drinking within the $30 \mathrm{~min}$ before IV flush; or inability of patients and their parents or guardians to speak and understand English. Children under 6 years of age were excluded because it has previously been shown that children less than 5 to 6 years of age are unable to properly communicate variations in gustation. $^{5}$

\section{Preparation of NS Solutions}

Each morning, commercially available NS (AVIVA container system, Baxter) was transferred to polypropylene syringes (BD, Franklin Lakes, New Jersey) from a polyolefin bag under a sterile laminar flow hood in the IV room within the CHEO Pharmacy Department; such syringes were stored for a maximum of $12 \mathrm{~h}$ before use. For the purposes of this study, NS prepared in this way is referred to as "fresh" NS. The polyolefin resins of this container system exhibit greater resistance to water transmission (i.e., leakage of volatile chemicals from the plastic into the NS) than the polypropylene resins of the prefilled syringes. ${ }^{6}$

\section{Data Collection}

A nurse from the vascular access team asked eligible patients or their guardians if they would be interested in participating in the study. If they agreed, the research assistant presented the written consent form to the patient or guardian as a scripted text. Flushing of each patient's IV tubing was performed with a PosiFlush $\mathrm{NaCl} \quad 0.9 \% 10-\mathrm{mL}$ sterile prefilled syringe (BD, Franklin Lakes, New Jersey) or with fresh NS (prepared as described above) according to a randomization list generated by the research randomizer and delivered to the nurse. The patient was blinded to the type of NS being administered.

Immediately after the flushing procedure, the investigator used a data collection sheet to gather baseline information and the patient's responses to a series of questions. The following baseline information was collected: patient's sex and date of birth, date and time of flushing, location of tubing flushed (central or peripheral), type of NS administered (prefilled syringe or fresh), and volume of NS administered. Next, the patient was asked a question about his or her experience with the NS flush. The patient was also asked about any visual and tactile disruptions. Finally, the patient was asked about taste and odour perceptions. Patients 6 to 10 years old used a validated visual hedonic scale to rate any disturbances in taste, touch, sight, and odour. This scale has been shown to be a reliable method for assessing sensory perceptions in children in this age group. ${ }^{5}$ Here, 0 represented the worst taste or odour imaginable and 100 represented the absence of taste or odour. Patients 11 to 18 years old were asked to measure taste, touch, sight, and odour perceptions with a numeric rating scale. Here, 0 represented an absence of taste or odour and 10 represented the worst taste or odour imaginable. This numeric scale was not validated. ${ }^{5}$

\section{Data Analysis}

Data were analyzed with SPSS software, version 20.0 (IBM, Armonk, New York). The categorical variables were summarized as frequencies and percentages. The measurable outcomes of the trial were total number of reported disturbances of odour and/or taste (overall occurrence rate) with NS from prefilled syringes and with NS from freshly prepared syringes. Statistical significance was determined using $\chi^{2}$ and Fisher exact tests, as appropriate. Any $p$ values less than 0.05 were considered 
statistically significant. Descriptive statistics are reported as means \pm standard deviation.

\section{RESULTS}

A total of 50 pediatric patients (mean age $13.4 \pm 3.8$ years) underwent NS flushing of IV tubing (25 patients with each type of NS) and were interviewed after the flushing procedure. Of these, 23 underwent flushing of central tubing and 27 underwent flushing of peripheral tubing.

The distribution of flush volumes was as follows: 41 patients $(82 \%)$ with $10 \mathrm{~mL}, 6$ patients $(12 \%)$ with $20 \mathrm{~mL}, 2$ patients (4\%) with $9 \mathrm{~mL}$, and 1 patient $(2 \%)$ with $8 \mathrm{~mL}$. Taste and/or odour disturbances were reported by 18 (72\%) of the 25 patients who underwent IV flush with NS from prefilled syringes (Figure 1 ) and by only 1 (4\%) of the 25 patients who underwent IV flush with fresh NS $(p<0.001)$ (Table 1). Taste disturbances were reported by $16(64 \%)$ of the patients who underwent IV flush with NS from prefilled syringes and by $1(4 \%)$ of the patients who underwent IV flush with fresh NS $(p<0.001)$ (Table 1). Similarly, odour disturbances were reported by 13 (52\%) of the patients who underwent IV flush with NS from prefilled syringes and by none of the patients who underwent IV flush with fresh NS $(p<0.001)$ (Table 1$)$.
There were no significant differences in taste and odour disturbances in relation to age, sex, or flush volume. As well, there was no significant difference in patients' answers to the opening question of the interview ("Did you experience anything after the saline injection?") in relation to type of NS preparation: 18 (72\%) of the 25 patients who underwent flushing with NS from prefilled syringes and 19 (76\%) of the 25 patients who underwent flushing with fresh NS reported "no experience" $(p=0.50)$. However, when responses to the opening question were analyzed by age group, $6(50 \%)$ of the 12 younger patients (6-10 years old) but only 7 (18\%) of the 38 older patients ( $11-18$ years old) reported an experience $(p=0.040)$.

Among the 13 patients who reported an odour disturbance, the most frequently reported type was salty (2 patients [15\%]) (Table 2). However, 4 (31\%) of the 13 patients who reported an odour disturbance were unable to describe the sensation in specific terms (Table 2). According to the numeric rating scale (from 0 to 10 , with 0 indicating no disturbance), the mean odour disturbance was $1.7 \pm 2.4$ among the 17 older patients who underwent IV flush with NS from prefilled syringes and $0.05 \pm$ 0.23 among the 19 older patients who underwent IV flush with fresh NS $(p=0.011)$. (The remaining 2 patients in the older age category were excluded from this analysis because they were asked to use the visual hedonic scale that was intended for younger patients.) According to the visual hedonic scale (from 0 to 100 ,

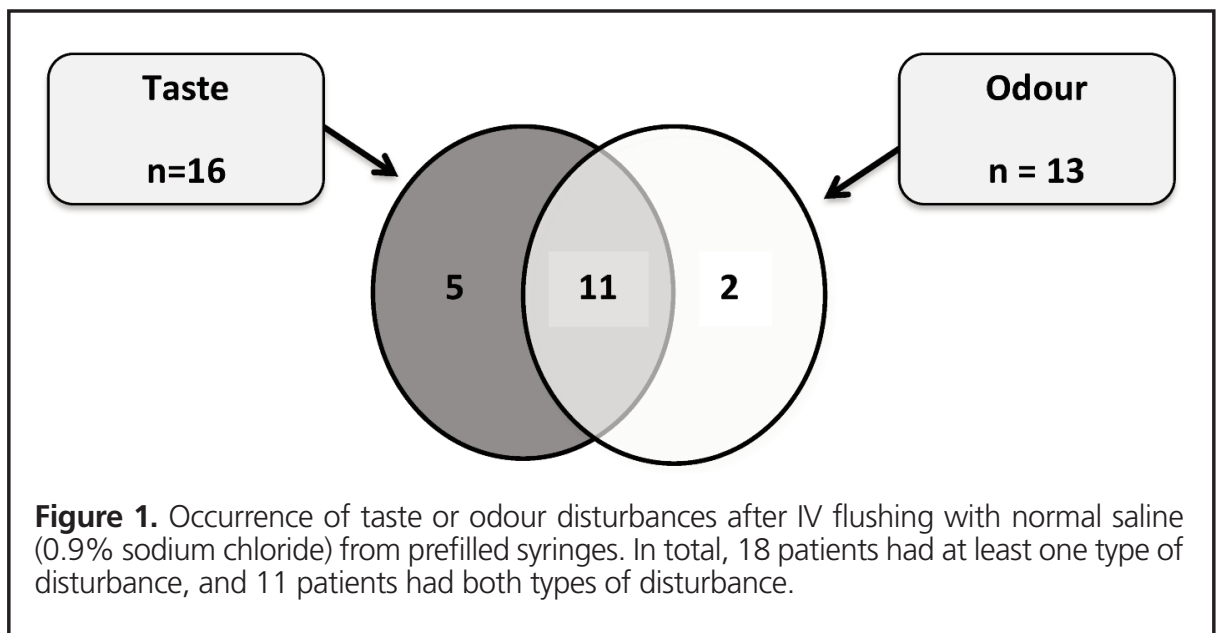

Table 1. Taste and Odour Disturbances after IV Flush with NS from Prefilled or Freshly Prepared Syringe

\begin{tabular}{|c|c|c|c|c|c|c|c|c|c|}
\hline \multirow[b]{3}{*}{ Type of Disturbance } & \multicolumn{9}{|c|}{ Age Group; No. (\%) of Participants } \\
\hline & \multicolumn{4}{|c|}{$6-10$ years } & \multicolumn{3}{|c|}{$11-18$ years } & \multicolumn{2}{|c|}{ All ages } \\
\hline & & $\begin{array}{l}\text { refilled } \\
n=8)\end{array}$ & & $\begin{array}{l}\text { Fresh } \\
(n=4)\end{array}$ & & $\begin{array}{l}\text { filled } \\
=17)\end{array}$ & $\begin{array}{c}\text { Fresh } \\
(n=21)\end{array}$ & $\begin{array}{c}\text { Prefilled } \\
(n=25)\end{array}$ & $\begin{array}{c}\text { Fresh } \\
(n=25)\end{array}$ \\
\hline Taste & 8 & $(100)$ & 0 & $(0)$ & 8 & (47) & $1 \quad(5)$ & $16(64)$ & $1 \quad(4)$ \\
\hline Odour & 6 & (75) & 0 & (0) & 7 & $(41)$ & $0 \quad(0)$ & $13(52)$ & $0 \quad(0)$ \\
\hline Taste or odour (or both) & 8 & $(100)$ & 0 & (0) & 10 & (59) & $1 \quad(5)$ & $18(72)$ & 1 (4) \\
\hline No disturbance & 0 & $(0)$ & 4 & $(100)$ & 7 & (41) & $20(95)$ & $7 \quad(28)$ & $24(96)$ \\
\hline
\end{tabular}

NS $=$ normal saline $(0.9 \%$ sodium chloride). 
Table 2. Description and Frequency of Taste and Odour Disturbances after IV Flushing with NS from Prefilled Syringes

\begin{tabular}{lrrrr} 
Description of Sensation & \multicolumn{2}{c}{$\begin{array}{c}\text { Taste } \\
(\boldsymbol{n}=\mathbf{1 6})\end{array}$} & \multicolumn{2}{c}{$\begin{array}{c}\text { Odour } \\
(\boldsymbol{n}=\mathbf{1 3})\end{array}$} \\
\hline Salty & 5 & $(31)$ & 2 & $(15)$ \\
Stale & 4 & $(25)$ & 1 & $(8)$ \\
Sour & 2 & $(13)$ & 0 & $(0)$ \\
Nauseating & 2 & $(13)$ & 0 & $(0)$ \\
Vinegar & 1 & $(6)$ & 0 & $(0)$ \\
Old coffee & 1 & $(6)$ & 0 & $(0)$ \\
Bitter & 0 & $(0)$ & 1 & $(8)$ \\
Decaying organic matter & 0 & $(0)$ & 1 & $(8)$ \\
Metallic & 0 & $(0)$ & 1 & $(8)$ \\
Swimming pool & 0 & $(0)$ & 1 & $(8)$ \\
Medicine & 0 & $(0)$ & 1 & $(8)$ \\
Pond water & 0 & $(0)$ & 1 & $(8)$ \\
Unable to describe & 1 & $(6)$ & 4 & $(31)$ \\
\hline
\end{tabular}

with 100 indicating no disturbance), the mean odour disturbance was $71.9 \pm 33.9$ among the 8 younger patients who underwent IV flush with NS from prefilled syringes and $100 \pm 0$ among the 4 younger patients who underwent IV flush with fresh NS $(p=0.14)$.

Among the 16 patients who reported a taste disturbance, the most frequently reported types of disturbance were salty (5 patients [31\%]) and stale (4 patients [25\%]). According to the numeric rating scale, the mean taste disturbance was $1.9 \pm$ 1.9 among the 17 older patients who underwent IV flush with NS from prefilled syringes and $0.11 \pm 0.46$ among the 19 older patients who underwent IV flush with fresh NS ( $p=0.002)$. According to the visual hedonic scale, the mean taste disturbance was $59.4 \pm 22.9$ among the 8 younger patients who underwent IV flush with NS from prefilled syringes and $100 \pm 0$ among the 4 younger patients who underwent IV flush with fresh NS $(p=0.002)$.

\section{DISCUSSION}

To the authors' knowledge, this study is the first to measure and compare taste and odour disturbances associated with 2 syringe preparations of NS in a pediatric population. Patients who underwent flushing of IV tubing with NS from prefilled syringes experienced significant taste and odour disruptions, whereas patients who underwent flushing with fresh NS experienced minimal disruptions of taste and odour. These findings are in agreement with those of Celetti and others ${ }^{1}$ and Kongsgaard and others, ${ }^{2}$ who previously assessed the occurrence of unpleasant sensations following flushing with NS from prefilled syringes. Bias was minimized in the current study by asking questions about potential disturbance of other senses and by blinding patients to the type of NS that they were receiving. However, the similarity of the current findings with those of Celetti and others ${ }^{1}$ indicate that efforts to reduce bias had no influence on the frequency of sensations reported.

It has previously been reported that taste and odour variations associated with flushing of IV tubing are caused by leakage of volatile substances into the NS solution from the polypropylene resin of prefilled syringes. ${ }^{2}$ The manufacturer of syringes used in the study by Kongsgaard and others ${ }^{2}$ identified volatile substances and their respective concentrations within the NS as follows: 2-methyl-2-propanol, 8.5 ppm; 2-methyl-2-butanol, 0.7 ppm; and ethyl-butyl-ether, $0.4 \mathrm{ppm}$. These substances have no known carcinogenic or teratogenic risks to humans. ${ }^{7-9}$ As well, there is no evidence in the literature indicating that these substances are toxic to patients at the concentrations detected in the NS solutions. Therefore, the primary concern with the use of prefilled syringes of NS is the patient's discomfort that can result from the unpleasant disturbance.

The intensity of the disturbances reported in this study was mild, according to data from the numeric scale and the validated hedonic scale. Furthermore, there was no statistically significant difference in odour intensity between younger patients who underwent IV flush with NS from prefilled syringes and those who underwent IV flush with fresh NS. This result indicates that the sensations reported by patients in this age group (6-10 years old) were of particularly mild intensity.

An interesting finding was the lack of a difference between the 2 groups with regard to the number of children who answered "no" to the question of whether they experienced anything after the saline injection, even though there were significant differences between the groups in terms of answers to subsequent questions pertaining specifically to taste and odour. These results indicate that many children who experienced taste and odour disturbances revealed this experience to the investigator only when asked specifically about these senses, possibly because the sensations reported were of only mild intensity. As such, patients may not have initially mentioned them because they were deemed unremarkable. This finding may also be explained by the fact that taste and odour disturbances experienced after flushing of IV tubing are intermittent and short-lived, and the sensation had passed by the time the investigator asked the initial question. However, the child then recalled the unpleasant experience when specifically asked about taste and odour disturbances in subsequent questions.

This study showed no difference in taste and odour disturbances in relation to flush volume. However, it is still important to consider the possibility of a dose-related effect. The flush volumes analyzed in this study ranged only between $8 \mathrm{~mL}$ and $20 \mathrm{~mL}$. Further studies would be necessary to investigate differences in disturbances outside this volume range.

One limitation of this study was the complexity of the opening question: "Did you experience anything after the saline 
injection?" Significantly more patients in the younger age group than the older age group answered this question in the affirmative. However, the research assistant observed that many of the children in the younger age group exhibited difficulty interpreting this question. This difficulty might have been related to a variety of factors, such as age, literacy level, culture, and language barriers. Therefore, the difference between age groups could be related to younger children having an inadequate understanding of the question. In future studies, use of less complex questions may be necessary to optimize interpretation by younger patients. The research assistant also observed that before undergoing flush of the IV tubing, many of the children commented on experiencing taste and odour disturbances during previous flushes. This represents another limitation to the study, as these children might have had preconceived expectations of a sensory disturbance, regardless of the type of NS preparation they actually received, which might have increased the likelihood of falsely reporting a disturbance. One final limitation is the fact that the research team was not blinded to the type of NS preparation that each child was receiving. Having a separate individual administer the questionnaire might further minimize bias in future trials.

Our interpretation of the literature is that the prefilled NS syringe is classified by Health Canada as a medical device, rather than a drug, because its indication is not accomplished by pharmacologic, immunologic, or metabolic means. ${ }^{10,11}$ Therefore, these prefilled devices are not subject to the tests for organic volatile impurities that are required for drug solutions. ${ }^{12}$ For several reasons, daily preparation of fresh syringes of NS is not a sustainable solution to sensory disturbances. Therefore, we recommend that prefilled NS syringes be classified as a drug product and that testing for organic volatile impurities be conducted on these devices to assess for substances leaching into solution from the plastic syringe.

\section{CONCLUSIONS}

This study has documented unpleasant sensory experiences for children after flushing of IV tubing with NS from prefilled syringes. These unpleasant sensations may be particularly disruptive for patients who are already experiencing sensory dysfunction because of chemotherapy or radiation treatments. ${ }^{2,4}$

\section{References}

1. Celetti SJ, Vaillancourt R, Pascuet E, Sharp D. Taste and/or odour disturbances in pediatric patients undergoing IV flush with normal saline administered by prefilled syringe. Can J Hosp Pharm. 2012;65(5):368-72.

2. Kongsgaard UE, Andersen A, Oien M, Oswald IA, Bruun LI. Experience of unpleasant sensations in the mouth after injection of saline from prefilled syringes. BMC Nurs. 2010;9:1-6.
3. Brisbois TD, Hutton JL, Baracos VE, Wismer WV. Taste and smell abnormalities as an independent cause of failure of food intake in patients with advanced cancer - an argument for application of sensory science. J Palliat Care. 2006;22(2):111-4

4. Hong JH, Omur-Ozbek P, Stanek BT, Dietrich AM, Duncan SE, Lee YW, et al. Taste and odor abnormalities in cancer patients. J Support Oncol. 2009; $7(2): 58-65$.

5. Sjövall J, Fogh A, Huitfeldt B, Karlsson G, Nylén O. Methods for evaluating the taste of paediatric formulations in children: a comparison between the facial hedonic method and the patients' own spontaneous verbal judgement. Eur J Pediatr. 1984;141(4):243-7.

6. Prefilled syringes: device suppliers meeting pharmaceutical standards. Hove, East Sussex (UK): ONdrugDelivery Ltd; [cited 2013 Jul 14]. Available from: www.ondrugdelivery.com/publications/Prefilled_syringes_\%2007.pdf

7. Ethyl tertiary butyl ether [material safety data sheet]. Rotterdam (Netherlands): Lyondell Chemie Nederland; 2004 Jul 29 [cited 2013 May 28]. Available from: www.bioethanol.ru/images/articles/MSDS-ETBE.pdf

8. 2-Methyl-2-butanol [material safety data sheet]. Georgetown (ON): Caledon Laboratories; 1998 Jun 9 [revised 2013 Jun; cited 2013 May 28]. Available from: www.caledonlabs.com/upload/msds/5090-5e.pdf

9. 2-Methyl-2-propanol [material safety data sheet]. Georgetown (ON): Caledon Laboratories; 1991 Aug 5 [revised 2013 Nov; cited 2013 May 28]. Available from: www.caledonlabs.com/upload/msds/7100-1e.pdf

10. Alert: errors with prefilled saline syringes when used to reconstitute or dilute medications. ISMP Can Saf Bull. 2012 [cited 2013 May 28];12(10):1-2. Available from: www.ismp-canada.org/download/safetyBulletins/2012/ ISMPCSB2012-10_ALERT_Errors_with_Prefilled_Saline_Syringes.pdf

11. Drug and medical device combination product decisions. Ottawa $(\mathrm{ON})$ : Health Canada; 1998 [updated 2014 Jul 21; cited 2014 Sep 12]. Available from: www.hc-sc.gc.ca/dhp-mps/alt_formats/hpfb-dgpsa/pdf/prodpharma/ combo_mixte_dec_pol-eng.pdf

12. Drug information for the health care professional. 27th ed. Rockville (MD); United States Pharmacopeial Convention; 2007. p. 2514-7.

David Mancini, BSc, is a student in the PharmD program, School of Pharmacy, University of Waterloo, Waterloo, Ontario.

Régis Vaillancourt, BPharm, PharmD, FCSHP, FFIP, is with the Children's Hospital of Eastern Ontario, Ottawa, Ontario.

Annie Pouliot, PhD, is with the Children's Hospital of Eastern Ontario, Ottawa, Ontario.

Alice Lin is a student in the Bachelor of Pharmacy program, School of Pharmacy, University of Waterloo, Waterloo, Ontario.

Diane Sharp, RN, CVAA $(C)$, is with the Children's Hospital of Eastern Ontario, Ottawa, Ontario.

Competing interests: None declared.

Address correspondence to:

Dr Régis Vaillancourt

Director of Pharmacy

Children's Hospital of Eastern Ontario

401 Smyth Road

Ottawa ON K1H 8L1

e-mail: rvaillancourt@cheo.on.ca 